\title{
The Critical Study of Exploring the Quality of Software in the Context of Reliability in Less Developed Countries
}

\author{
Sumaira Hussain \\ Sindh Madressatul Islam \\ University, Karachi, Pakistan \\ Department of Computer \\ Science
}

\author{
Syed Asif Ali \\ Sindh Madressatul Islam \\ University, Karachi, Pakistan \\ Department of Computer \\ Science
}

\author{
Abdul BasitDogar \\ Tsinghua University, \\ Beijing,China \\ Department of Computer \\ Science
}

\begin{abstract}
Software development and evaluation is the most difficult task in software engineering. The future of the software industry depends upon the development of software. For this purpose quality is considered essential step in designing software. Quality of software is dependable upon different aspects but the dream of software quality is not feasible without software reliability. Reliability of software is the chance of performing operation without any failure in a particular environment for a specific period. This paper is basically concerned with improving quality of software. The quality is the instrument that can predict future of the software in industry. This paper presents the strategy to measure and maintain quality of software. The research is based on the reviews collected through questionnaire and visits to persons concerned with the designing, maintaining and utilizing software. It also discusses some techniques like CMM, Process Maturity Hierarchy used for measuring the reliability of software. The solution to this problem is to focus on the weaknesses found through the research. The first step towards formulating reliable software is to trace all the facts that are responsible for failure of software. Later each issue will be given individual attention for its resolution. At the end reliable software will be generated.
\end{abstract}

\section{General Terms}

Software Quality, Software Reliability, Agile Method, VProcess Model and System Reliability

\section{Keywords}

Software Quality, Software Engineering, Reliability, Testing, Software Quality Assurance and Agile Model

\section{INTRODUCTION}

Software acts as a controller of computer from centuries. Collection of programs that can make the hardware utilizable is termed as software. Software industry has become the important part of progress in technology. As the reliance on software increased, maintenance of its quality becomes more essential. Software quality measures the compatibility level of the software design, and its adaptation to that particular design [1]. Quality of software is dependable upon different aspects but the concept of software quality is incomplete without software reliability. Reliability of software is the chance of performing operation without any failure in a particular environment for a specific period.

"Software quality cannot be reduced to a single number or parameter. Reliability is the important parameter about software quality"[2].

Uses of engineering field techniques to create effective software give rise to the need of an approach to independently determine software reliability [3]. The need was highlighted by the response and general observation of software users and designers on getting the desired output. In other words, software sometimes performs strangely, results into failure, people loses their costly machines and data due to the software unpredictable behavior. The significance of software reliability increases with its application to economic and life-supporting systems.

With the passage of time companies started using Quality Management Standards in software production. Major software engineering standards developed in ISO/IEC JTC1/SC7 recently are ISO/IEC 12207 (1995)-Software Life Cycle Processes, and ISO/IEC TR 15504 (1999)-Software Process Assessment. In addition, ISO/IEC CD 15288 (1999)-System Life Cycle Processes is under development. Last decade has presented numerous software engineering standards and models, such as TickIT, ISO 9001, CMM, ISO/IEC 12207, and ISO/IEC 15504 (SPICE). ISO 9001standard are most famous in software engineering according to a recent worldwide survey, after that CMM and ISO/IEC TR 15504 are in demand [4].

A variety of software engineering standard and models, international, regional, and internal, have been developed in the last decade and approximately all current software engineering standards foundation lies on general quality system awareness on software development. Although this way has been proven convenient in conservative industry, but still verification of its effectiveness and impact over the design has made software engineers conscious and is also not predictable for software industry.

\section{"Software Reliability is the probability of failure-free software operation for a specified period of time in a specified environment" [5].}

One essential aspect that affects system reliability is software reliability. This need is an outcome from the observations made by all types of users that software is not fulfilling user's expectations. It means that, software results some unexpected results during its execution or behave strangely with the data which is processed. Therefore the need to check reliability of software becomes more vital.

System reliability can be achieved by two main strategies. First one emphasizes on the use of simple and vigorous design. Simple design has lots of benefits like easy to understand, easy to control and easy to test. Second one is to avoid repetition or superfluity. This reduces the chances of failure of both primary component and its backup simultaneously.

\section{MATERIAL AND METHODS}

The Analytical method is used to check the development of reliable software in organizations. The quantitative data collected through this survey cover through the following questions: 
1. What sorts of software are designed in this organization?

2. How data is collected from the client?

3. What problems are faced during development of software?

4. Which models are implemented in designing software?

5. What is the ratio of success or failure of the software?

6. What errors are reported after the use of client or product development?

7. What strategies are implemented to tackle these problems?

8. What are the major issues in developing the quality software?

9. What methods are adopted to improve the quality of software?

10. How much reliable a software is?

11. What are the characteristics of quality software?

12. How reliability is measured?

13. What is the relationship between the quality \& the productivity?

14. What kinds of trade-offs are made between software quality and time to market?

15. Are there any published case studies of design of experiments in testing?

16. Does this organization have a separate Quality Assurance/ Quality Control Department?

17. What are the developers: tester's ratio?

18. Does this organization possess an independent testing team?

19. Is software testing performed in working projects?

\section{PROPOSED SYSTEM}

\subsection{Reason for Proposing the System}

The qualitative and quantitative survey has highlighted some flaws in the process of quality assurance. These weaknesses are as follows:

- Data collection methodologies are not appropriate

- Frequent change in requirements by customers

- $\quad$ Time deadline

- Mostly use of Agile model

- Targets not achieved

- $\quad$ Errors in planning, reliability and maintainability

- Customers not satisfied with end-product

- No strategy for quality improvement

- $60 \%$ software's are not reliable
- Instability between productivity and quality

- $\quad$ Case-studies are not published

- Quality Assurance Departments are not established

- Absence of independent testing teams

- Developers and testers ratio is not equal

\subsection{Proposed system}

There are many processes available to stable quality of software. Agile and V-process models are the most re-known model in this regard. V-model works on software development through verification and validation process. Agile method is based on iterative and incremental development of software.

The solution to remove all the faults mentioned earlier is a combination of both Agile and V-process model is recommended. The following two models shall be adopted to remove errors and generate quality software

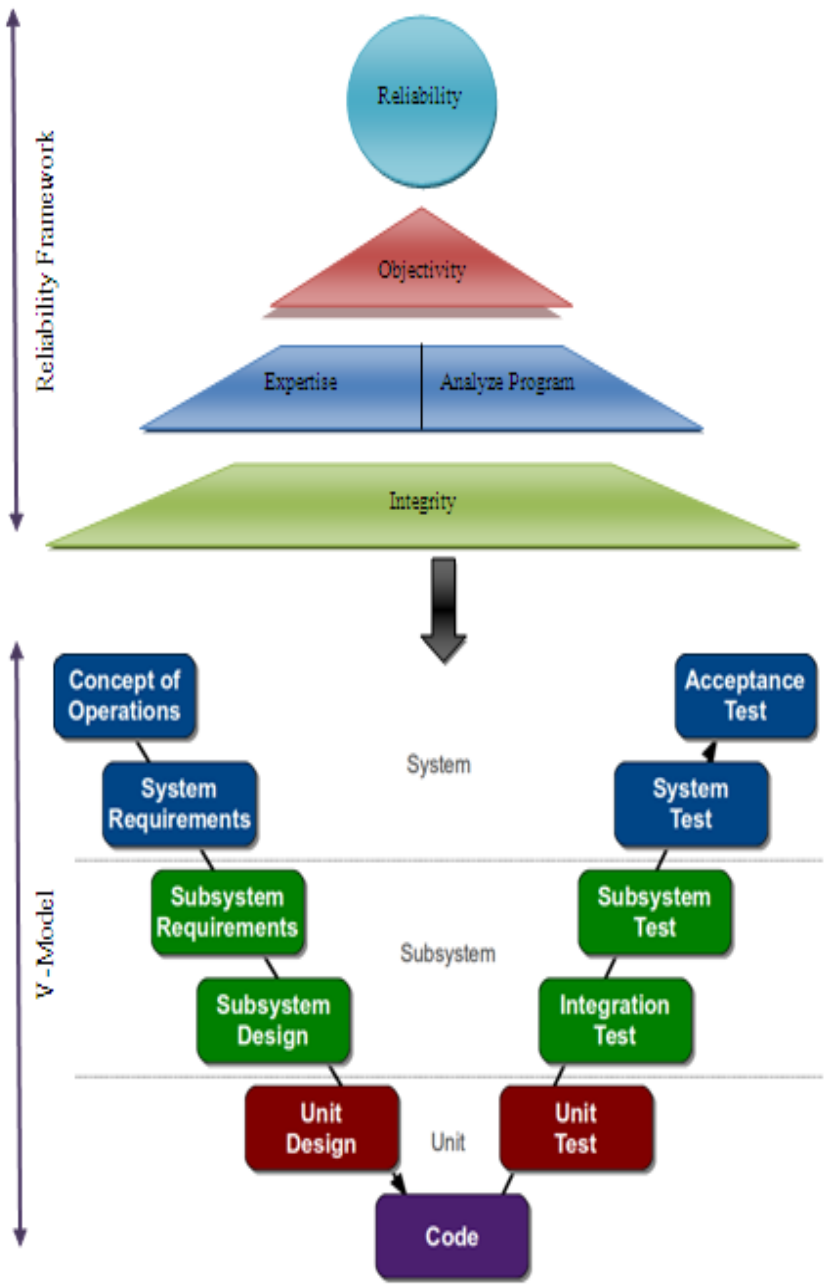

Figure1. Proposed Model of Reliability to Achieve Quality Software through V-Process Model 


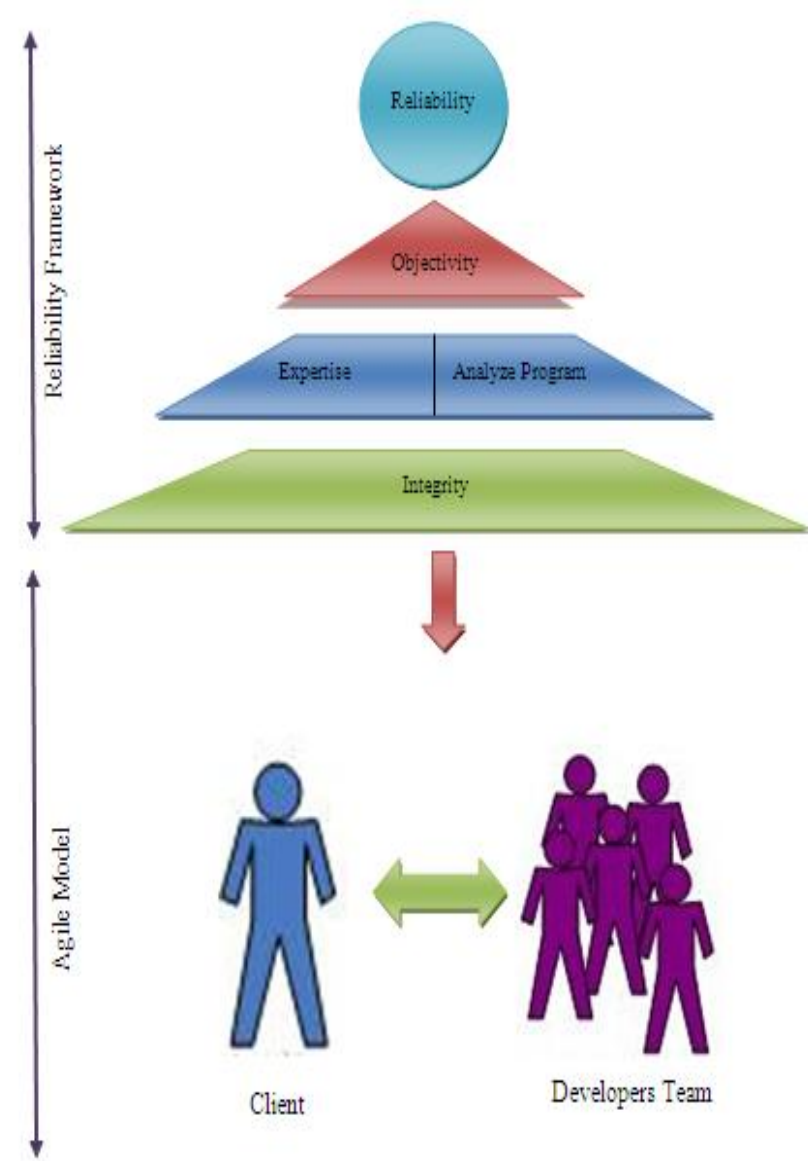

Figure2. Proposed Model of Reliability to Achieve Quality Software through Agile Model

\section{CONCLUSION}

This research focus on quality of software in context of reliability. In less development countries there is lack of awareness regarding quality of software development. Result of this, when software product ready to deploymentthe quality is not up to standard. This work highlighted flaws in the development of software and research also provides a framework that help to attain reliable quality software.

A hybrid model is proposed for developers and users to generate quality software which is mishmash of two models.

Software quality is the most affected area of software in less developed countries. The proposed system provide economical solution toward quality of software for less developed countries.

The graph in figure 3 shows the trends found in software industry.
Table1. Survey Questions on Software Reliability \& Responses

\begin{tabular}{|c|c|}
\hline Questions & Responses \\
\hline $\begin{array}{l}\text { What sorts of software are designed in this } \\
\text { organization? }\end{array}$ & $60 \%$ \\
\hline How data is collected from the client? & $40 \%$ \\
\hline $\begin{array}{l}\text { What problems are faced during development } \\
\text { of software? }\end{array}$ & $90 \%$ \\
\hline $\begin{array}{l}\text { Which models are implemented in designing } \\
\text { software? }\end{array}$ & $25 \%$ \\
\hline $\begin{array}{l}\text { What is the ratio of success or failure of the } \\
\text { software? }\end{array}$ & $80 \%$ \\
\hline $\begin{array}{l}\text { What errors are reported after the use of client } \\
\text { or product development? }\end{array}$ & $90 \%$ \\
\hline $\begin{array}{l}\text { What strategies are implemented to tackle these } \\
\text { problems? }\end{array}$ & $20 \%$ \\
\hline $\begin{array}{l}\text { What are the major issues in developing the } \\
\text { quality software? }\end{array}$ & $40 \%$ \\
\hline $\begin{array}{l}\text { What methods are adopted to improve the } \\
\text { quality of software? }\end{array}$ & $20 \%$ \\
\hline How much reliable a software is? & $80 \%$ \\
\hline $\begin{array}{l}\text { What are the characteristics of quality } \\
\text { software? }\end{array}$ & $70 \%$ \\
\hline How reliability is measured? & $60 \%$ \\
\hline $\begin{array}{l}\text { What is the relationship between the quality \& } \\
\text { the productivity? }\end{array}$ & $67 \%$ \\
\hline $\begin{array}{l}\text { What kinds of trade-offs are made between } \\
\text { software quality and time to market? }\end{array}$ & $50 \%$ \\
\hline $\begin{array}{l}\text { Are there any published case studies of design } \\
\text { of experiments in testing? }\end{array}$ & $33 \%$ \\
\hline $\begin{array}{l}\text { Does this organization have a separate Quality } \\
\text { Assurance/ Quality Control Department? }\end{array}$ & $67 \%$ \\
\hline What are the developers: tester's ratio? & $70 \%$ \\
\hline $\begin{array}{l}\text { Does this organization possess an independent } \\
\text { testing team }\end{array}$ & $50 \%$ \\
\hline $\begin{array}{l}\text { Is software testing performed in working } \\
\text { projects? }\end{array}$ & $100 \%$ \\
\hline
\end{tabular}




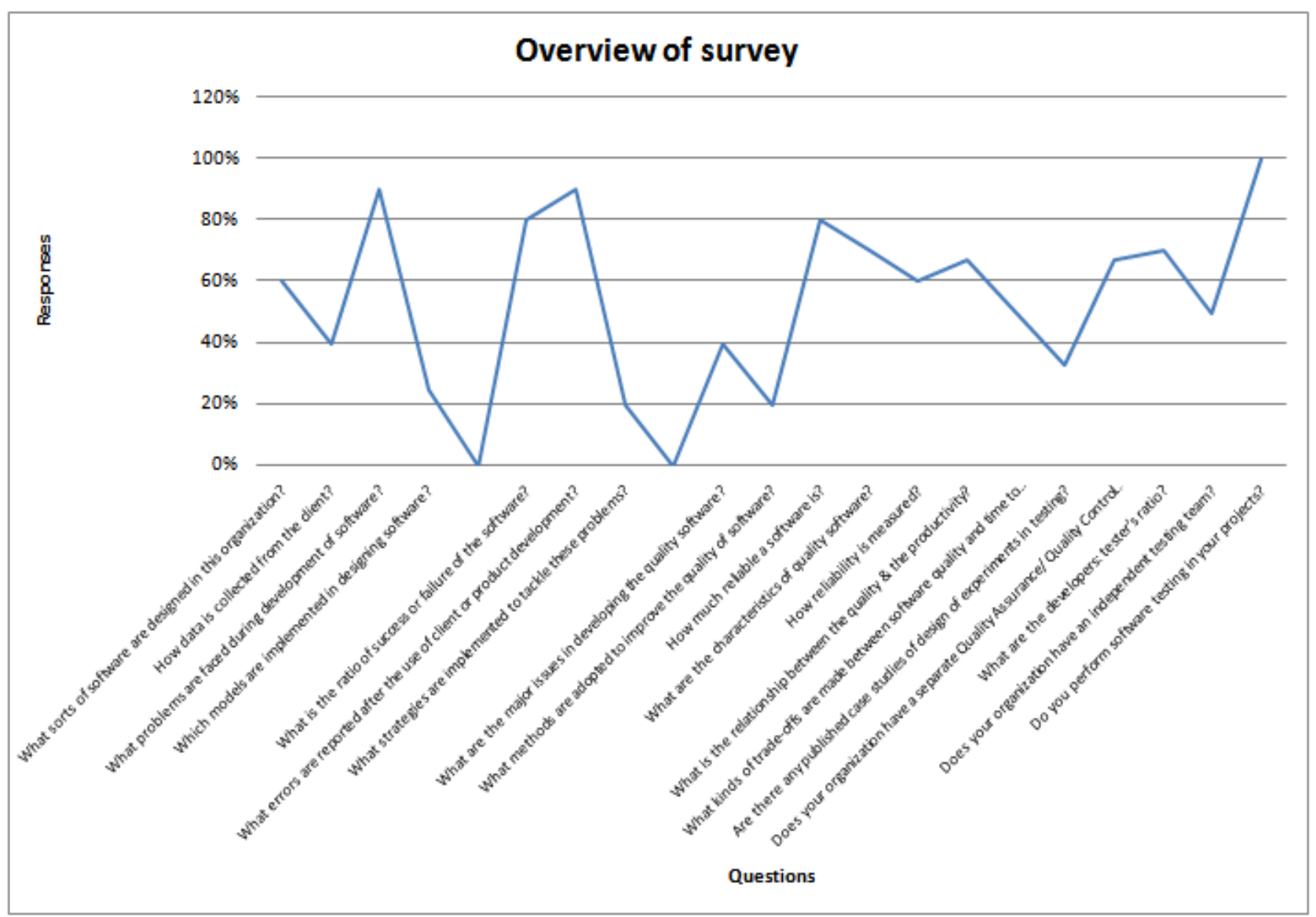

Figure3. Graph of survey questions and its Responses

\section{REFERENCES}

[1] Dromey, R.G. 1994. Software Quality and Productivity Improvement. IEEE Trans. on Software Engg. (Nathan, Australia). pp. 18-41.

[2] Kelkar, S. A. 2007. Software Engineering: A Concise Study. $1^{\text {st }}$ Ed. Prentice Hall of India Pvt. Limited. (New Delhi, India). pp. 1-940. ISBN: 978-8120332720.

[3] Li, N. and Y. K. Malaiya. 1993. Enhancing Accuracy of Software Reliability Prediction. IEEE Int. Symp. on
Software Reliability Engineering. (Colorado, USA). pp. 71-79.

[4] Wang, Y. 2002. Software Engineering Standards: Review and Perspectives, Handbook of Software Engineering and Knowledge Engineering.World Scientific Publisher. (Alberta, Canada).1: 15-29. ISBN: 978-981-02-4973-1.

[5] ANSI/IEEE. 1990.IEEE Standard Glossary of Software Engineering Terminology. The MITRE Corporation Leonard Tripp, The Boeing Company.(CA, USA). 16: 184. ISBN: 978-0-7381-0391-4. 